\title{
Conductivity and structure of polyamide/silver iodide nanocomposite
}

Yoshie Fujimori, ${ }^{1}$ Yasuo Gotoh, ${ }^{1 *}$ Akio Kawaguchi, ${ }^{2}$ Yutaka Ohkoshi, ${ }^{1}$ Masanobu Nagura ${ }^{1}$

${ }^{1}$ Faculty of Textile Science and Technology, Shinshu University 3-15-1 Tokida, Ueda,

Nagano, 386-8567, Japan

${ }^{2}$ Research Reactor Institute, Kyoto University, Kumatori, Osaka, 590-0494, Japan.

*Corresponding author (e-mail: ygotohy@shinshu-u.ac.jp) 


\section{ABSTRACT}

In this study, the structure and properties of an organic-inorganic composite material, prepared from nylon 6 doped with fine particles of silver iodide (AgI), were examined. The preparation of the composite involved the complexation of nylon 6 with polyiodide ions such as $\mathrm{I}_{3}{ }^{-}$and $\mathrm{I}_{5}{ }^{-}$by immersion in an iodine-potassium iodide ( $\left.\mathrm{I}_{2}-\mathrm{KI}\right)$ aqueous solution followed by reaction in an $\mathrm{AgNO}_{3}$ aqueous solution, resulting in the in-situ formation of $\beta$-AgI fine particles within the nylon 6 matrix. The AgI content formed in the composite was dependent on the immersion temperatures of the $\mathrm{I}_{2}-\mathrm{KI}$ and $\mathrm{AgNO}_{3}$ solutions. Lower solution temperatures resulted in larger amounts of $\mathrm{AgI}$ in the composite. This method readily provided a composite with a high content of $\mathrm{AgI}$ in nylon 6, and conductivity of approximately $10^{-5} \Omega^{-1} \mathrm{~cm}^{-1}$. In a uniaxially oriented nylon 6 matrix, AgI particles precipitated with anisotropic shape, which was caused by the orientation of the precursor polyiodide ions. The structure of the oriented composite provided the anisotropic conductivity. Additionally, the composite exhibited high antibacterial property. It is considered that the procedure used in this study is a unique method for the preparation of organic-inorganic composites.

Key words: nylon 6; silver iodide; organic-inorganic composite; polyiodide; conductivity; antibacterial property 


\section{INTRODUCTION}

The synthesis and the properties of silver iodide (AgI) have been actively researched, mainly due to its properties of photosensitivity and superionic conductivity. ${ }^{1-3}$ Generally, AgI crystals exhibit three phases, designated as $\alpha, \beta$, and $\gamma$, under atmospheric pressure and in order of decreasing temperature. ${ }^{4}$ At room temperature and ambient atmospheric pressure, the two phases of $\beta$-AgI and $\gamma$-AgI may exist. In $\beta$-AgI, which is stable below $147^{\circ} \mathrm{C}$, the iodine ions are arranged in a hexagonal close-packed (hcp) lattice with the silver ions being tetrahedrally coordinated to each of the iodides (a wurtzite structure). In $\gamma$-AgI, the iodine ions are arranged in a face-centered cubic (fcc) lattice with the silver ions tetrahedrally coordinated to the iodine ions, and $\gamma$-AgI transforms to $\beta$-AgI at $137^{\circ} \mathrm{C}$. Above $147{ }^{\circ} \mathrm{C}$, $\beta$-AgI transforms into $\alpha$-AgI, in which the iodine ions form a body-centered cubic (bcc) lattice. The level of ionic conductivity of $\alpha-\mathrm{AgI}$ is extremely high and comparable to those of liquid electrolytes $\left(\approx 10^{0} \Omega^{-1} \mathrm{~cm}^{-1}\right)$. Since the discovery of this high conductivity, ${ }^{5} \mathrm{AgI}$ has been called a "solid superionic conductor" and has attracted wide interest. In contrast, $\beta$-AgI and $\gamma$-AgI, which are stable at lower temperatures, exhibit ionic conductivity that is 6 orders of magnitude lower than that of $\alpha$-AgI. Attempts have been made to obtain AgI or its composites with higher ionic conductivity at room 
temperature. For example, the pseudobinary system of $\mathrm{AgI}(90.1 \mathrm{~mol} \%)-\mathrm{Ag}_{3} \mathrm{BO}_{3}(9.9 \mathrm{~mol} \%)$ has superionic $\alpha$-AgI stabilized at room temperature by a melt-quenching technique, and exhibits high ionic conductivity of ca. $10^{-1} \Omega^{-1} \mathrm{~cm}^{-1}{ }^{6}$ Compounding of rubidium iodide with $\mathrm{AgI}\left(\mathrm{RbAg}_{4} \mathrm{I}_{5}\right)$ resulted in conductivity in the order of $10^{-1} \Omega^{-1} \mathrm{~cm}^{-1} \cdot{ }^{7,8} \mathrm{~A}$ new type of AgI with a structure similar to a mixture of $\beta$-AgI and $\gamma$-AgI has also been reported to show high conductivity of $10^{-3} \Omega^{-1} \mathrm{~cm}^{-1}$. 9 The conductivity of AgI depends not only on the crystal form, but also the particle size. That is, smaller particles of silver halides exhibit higher ionic conductivity, and therefore, much attention has recently been paid to the preparation and characterization of AgI nanoparticles. ${ }^{10-14}$

Nowadays, high-function and high-performance materials are demanded in various fields such as energy-saving, resource-saving, optics, and electrical and electronic engineering. Organic/inorganic hybrids or nanocomposite materials have been actively developed to obtain new properties that each component does not show independently. Representative of such materials is nanocomposite materials composed of inorganic nanoparticles introduced into an organic polymer matrix. These nanocomposites, with introduced nano-sized metal and semiconducting particles, have very different properties from those of the bulk composite materials, such as characteristic optical, electrical, and magnetic properties caused by the quantum size effect. ${ }^{15-19}$ We have reported preparative methods and optical properties for some nanocomposites with nanoparticles (e.g., silver metal, silver sulfide, copper 
sulfide and copper iodide) introduced into a matrix of nylon 6 or polyacrylic acid. ${ }^{20-22}$

$\mathrm{AgI}$ is an attractive inorganic compound, and thus it is considered that $\mathrm{AgI}$ is a good candidate as a component of a nanocomposite material. Composites with AgI introduced into an inorganic matrix have been reported; for example, AgI nanoparticles were precipitated in-situ in nanopores of alumina prepared by the anodizing process. ${ }^{23}$ As a result, the crystal transition from $\beta$-AgI to $\alpha$-AgI interestingly occurred at higher temperature $\left(160^{\circ} \mathrm{C}\right)$, compared with that of bulk $\mathrm{AgI}\left(147^{\circ} \mathrm{C}\right)$, because the nanopores of the alumina matrix strongly restrict the thermal motion of AgI. However, few researchers have reported a nanocomposite of $\mathrm{AgI}$ in an organic polymer matrix, although it is expected that the properties of AgI particles in a nanocomposite would be different from the bulk properties.

We successfully prepared a nylon 6-AgI composite via a precursor complex of polymer-polyiodide ions, and briefly reported some interesting properties. ${ }^{24}$ For example, the transition temperature of $\beta$-AgI to $\alpha$-AgI for the composite was more than $20^{\circ} \mathrm{C}$ lower than that of bulk $\mathrm{AgI}\left(147^{\circ} \mathrm{C}\right)$. The ionic conductivity of the composite was much higher than that of pure $\beta$-AgI or $\gamma$-AgI, although the volume fraction of $\mathrm{AgI}$ in the insulating nylon 6 matrix was only about 20\%. AgI was formed in the nylon 6 matrix by the reaction of precursor polyiodide ions $\mathrm{I}_{\mathrm{n}}^{-}(\mathrm{n}=3,5 \cdots)$ with $\mathrm{Ag}^{+}$ions, and the subsequent in-situ precipitation of AgI. 
However, the accumulated results from the study of nylon 6-AgI composites have not yet been reported in detail. This report deals with the influence of the preparation conditions for AgI formation in a nylon 6 matrix via a nylon 6-polyiodide ion complex, on the properties of the resulting composites. That is, we examined conditions such as the immersion temperature of the iodine-potassium iodide or silver nitrate aqueous solutions, and the molecular orientation of nylon 6 chains, which influence the amount, structure and the properties of $\mathrm{AgI}$ formed in nylon 6, and we also investigated the reaction mechanism of polyiodide ions and $\mathrm{Ag}^{+}$ions.

\section{EXPERIMENTAL}

\section{Materials}

Biaxially stretched nylon 6 (random nylon 6) film (Unitika Co. Ltd. Japan) with a thickness of $15 \mu \mathrm{m}$ shows a random distribution of the crystallite orientation in the film plane. Uniaxially stretched nylon 6 (drawn nylon 6) film was prepared using nylon 6 pellets (Toray Industries, Inc.) by compression with a hot press machine at $255^{\circ} \mathrm{C}$ and $5 \mathrm{MPa}$, followed by quenching of the film in ice water. The quenched film was then drawn in an oven at $150^{\circ} \mathrm{C}$, and annealed for $2 \mathrm{~h}$. The resulting film thickness was ca. 40 $\mu \mathrm{m}$.

Iodine $\left(\mathrm{I}_{2}\right)$, potassium iodide $(\mathrm{KI})$, and silver nitrate $\left(\mathrm{AgNO}_{3}\right)$ were purchased from Wako Pure 
Chemical Industries, Ltd.

\section{Sample preparation}

Preparation of nylon 6-AgI composites was performed by the following method. Firstly, a nylon 6 film was immersed in $\mathrm{I}_{2}-\mathrm{KI}$ aqueous solution $\left(\mathrm{I}_{2} 0.15 \mathrm{~mol} / \mathrm{L}\right.$, KI $\left.3.3 \mathrm{~mol} / \mathrm{L}\right)$ at a prescribed constant temperature, to obtain a dark brown film of nylon 6-polyiodide complex. (This process is called "primary doping"). Secondly, the complex film was immersed in $1 \mathrm{~mol} / \mathrm{L} \mathrm{AgNO}_{3}$ aqueous solution at a prescribed constant temperature. (This process is called "secondary doping"). Consequently, AgI fine particles were formed in the nylon 6 matrix, and a pale yellowish composite film was obtained. The prepared composites were then washed with distilled water. For the drawn nylon 6 film, the film was fixed with a Teflon plate to prevent shrinkage of the samples during each doping process. The immersion time of random nylon 6 films was $1 \mathrm{~h}$ for both the primary and secondary doping, while the immersion time for the drawn nylon 6 films was $1 \mathrm{~h}$ for the primary doping and $4 \mathrm{~h}$ for the secondary doping. These doping times were within the saturation condition for each doping. Longer doping time for the drawn nylon 6 film is attributed to the thicker film thickness.

Neat bulk AgI powder for comparison was prepared by mixing of $\mathrm{AgNO}_{3}$ and $\mathrm{KI}$ aqueous solutions with equivalence. The molar ratio of $\mathrm{Ag}$ and $\mathrm{I}$ of the neat $\mathrm{AgI}$ was 1.00 , which was determined by 
energy dispersive $\mathrm{X}$-ray analysis, indicating the high purity of AgI.

\section{Measurements}

X-ray diffraction (XRD) profiles were obtained with a Rigaku Rotaflex RU-200B X-ray generator equipped with a Rigaku PMG-GA goniometer. The X-ray source was Ni-filtered $\mathrm{Cu}-\mathrm{Ka}$ radiation $(0.15418 \mathrm{~nm})$ generated at $40 \mathrm{kV}$ and $150 \mathrm{~mA}$. X-ray photographs were taken using a Rigaku R-AXIS-DS3 imaging plate (IP) system.

Small angle X-ray scattering (SAXS) images were obtained with the synchrotron radiation X-ray of beam line of BL-15A in Photon Factory (PF) of High Energy Accelerator Research Organization (KEK). The applied X-ray wavelength was $0.15 \mathrm{~nm}$. The diameter of X-ray beam was $0.35 \mathrm{~mm}$ $($ vertical $) \times 0.53 \mathrm{~mm}$ (horizontal) at focus point. SAXS image was taken by a $1000 \times 1018$ pixel CCD camera. The camera length was determined using lead stearate $(\mathrm{StPb})$. The intensity profiles along the diffraction angle were taken from the obtained SAXS image.

Electrical conductivity was obtained by alternating current process using an electrical resistance measurement system (ITK Co. Japan, DVA-225). The frequency was $1 \mathrm{krad} \mathrm{sec}^{-1}$ (ca. $159 \mathrm{~Hz}$ ). The electrode spacing was $1 \mathrm{~cm}$, and the sample size was $3 \mathrm{~cm}$ long and $1 \mathrm{~cm}$ wide. Platinum was sputtered as an electrode on a sample because of diminishing of contact resistance. The measurement was 
conducted by a 2-point method after the checking of standard resistors. Impedance measurement was carried out with a Solartoron 1296 and SI 1260 system.

Scanning electron microscope (SEM) observation was conducted by a Hitachi S-2380N. The sample cross-section was prepared with a microtome using a diamond knife.

Polarized Raman spectroscopy was measured with an S. T. Japan Inc, HoloLab-5000 equipped with an MK-II filtered probe head using Nd:YAG laser beam of $532 \mathrm{~nm}$ generated at $50 \mathrm{~mW}$. The measurement was carried out under the conditions of resolution of $2.5 \mathrm{~cm}^{-1}$, exposure time of $3 \mathrm{~s}$ and summation of 10 times.

Thermogravimetric analysis (TGA) was measured with a Rigaku ThermoPlus II TG-DTA at a heating rate of $10{ }^{\circ} \mathrm{C} \mathrm{min}^{-1}$ in an air flow.

Antibacterial property was evaluated based on JIS L 1902 protocol. The colony forming units of bacteria on culture media with the composite were measured after incubation at $37{ }^{\circ} \mathrm{C}$ for $18 \mathrm{~h}$. The composite used in this measurement was prepared by immersions of nylon 6 in the $\mathrm{I}_{2}$-KI solution at $20{ }^{\circ} \mathrm{C}$ for $1 \mathrm{~min}$, and the $\mathrm{AgNO}_{3}$ solution at $20^{\circ} \mathrm{C}$ for $5 \mathrm{~min}$.

\section{RESULTS AND DISCUSSION}




\section{Dependence of AgI formation on treatment temperature}

Fig. 1 shows an XRD pattern of the nylon 6-AgI composite film and bulk $\beta$-AgI powder. The crystal form of $\mathrm{AgI}$ is basically assigned as $\beta-\mathrm{AgI},{ }^{25}$ however, the presence of $\gamma$-AgI and other crystal forms cannot be completely excluded, because the main diffraction peaks of $\gamma$-AgI overlap with those of $\beta-\mathrm{AgI}$, which is difficult to distinguish. In this study, the crystal form of $\mathrm{AgI}$ is represented as $\beta$ - $\mathrm{AgI}$ for convenience. From the XRD pattern of the composite, the width of the diffraction peaks is much broader, indicating that the crystallinity of AgI is considerably lower than that of bulk AgI.

Firstly, we studied the influence of the immersion temperature of the $\mathrm{I}_{2}-\mathrm{KI}$ aqueous solution for primary iodine doping on the amount of $\mathrm{AgI}$ formed in the nylon 6-AgI film. The immersion temperature of the secondary doping $\mathrm{AgNO}_{3}$ aqueous solution was fixed at $20^{\circ} \mathrm{C}$ for this measurement.

The resulting composite films were flexible, and the strength was high enough that the materials could be handled. Fig. 2 indicates the weight gain of the composites and the volume fraction of AgI in the composites prepared at different immersion temperatures of $\mathrm{I}_{2}-\mathrm{KI}$ aqueous solution. The weight gain was determined by calculating the difference between the weights of the nylon 6 and nylon 6-AgI films. The samples were stored at $25{ }^{\circ} \mathrm{C}$ and $65 \% \mathrm{RH}$ overnight before weight measurements. The moisture contents for each samples and neat nylon 6 are almost $3 \mathrm{wt} \%$, thus the influence of the moisture 
content was small. So we calculated the weight gain without consideration of moisture contents (The same holds for Fig. 3 and Fig.4). The weight gain for each composite was measured using three or four sample sheets, and the error bar was determined from scattered values. Lower immersion temperatures of the $\mathrm{I}_{2}-\mathrm{KI}$ aqueous solution resulted in greater weights of the nylon 6-AgI films. The weight gain of the composites prepared at immersion temperatures of $0{ }^{\circ} \mathrm{C}$ and $20{ }^{\circ} \mathrm{C}$ were $130 \mathrm{wt} \%$ and $105 \mathrm{wt} \%$, respectively. These values exceed the weight of the nylon 6 matrix and are extremely high for a filler material. The content of AgI in the composite could also be arbitrarily controlled by changing the concentration of the $\mathrm{I}_{2}-\mathrm{KI}$ solution.

To elucidate the relation of the weight gain from $\mathrm{AgI}$ with the immersion temperature of $\mathrm{I}_{2}-\mathrm{KI}$ solution, the amount of sorbed iodine component was measured, because the iodine component is converted to AgI. Fig. 3 shows the dependence of the amount of iodide component sorbed in the nylon 6 film on the immersion temperature for primary iodine doping. The amount of sorbed iodide component was obtained by the weight change of the nylon 6 to nylon 6-iodide complex after sufficient drying at room temperature under reduced pressure. In this case, potassium ions were contained as a counter ion of iodide ions in the nylon 6-iodide complex film, but the amount of the potassium component was very limited; e.g. only $1.6 \mathrm{wt} \%$ of potassium ions were contained in the nylon 6-iodide complex film immersed in $\mathrm{KI}^{-} \mathrm{I}_{2}$ solution at $20{ }^{\circ} \mathrm{C}$. Thus, the content of potassium was 
ignored in this discussion. The weight gain after primary doping due to the iodide component increased with the decrease in the immersion temperature. This means that the complexation of nylon 6 with polyiodide ions such as $\mathrm{I}_{3}{ }^{-}$and $\mathrm{I}_{5}{ }^{-}$occurs more readily at lower temperature, which agrees with the fact that the iodide component is sorbed more easily at lower temperatures. ${ }^{26,27}$ For each composite, the amount of $\mathrm{AgI}$ in the nylon 6-AgI composite is approximately twice that of the sorbed iodide component in the nylon 6 film. Consequently, it can be said that the amount of iodide component reflects the amount of AgI in the resultant film.

Next, the influence of the immersion temperature of the $\mathrm{AgNO}_{3}$ aqueous solution for secondary silver doping on the amount of AgI formed in nylon 6 film was studied. Fig. 4 shows the weight gain of composites prepared at different immersion temperatures of the $\mathrm{AgNO}_{3}$ solution. In this case, the immersion temperature of the $\mathrm{I}_{2}-\mathrm{KI}$ solution was fixed at $20{ }^{\circ} \mathrm{C}$. Weight gain was achieved by the same procedure as that used for the results presented in Fig. 2. The weight gain of nylon 6-AgI was increased with the decrease in the temperature for secondary doping, as shown in Fig. 4. However, the rate of change in the amount of AgI formed in the composites is less dependent on the immersion temperature of the $\mathrm{AgNO}_{3}$ solution, compared with the temperature dependence of primary iodine doping. Therefore, the amount of $\mathrm{AgI}$ in the composite film depends more on the amount of doped iodine component. A lesser amount of AgI resulted from a higher secondary doping temperature, and it was 
confirmed that a small amount of $\mathrm{AgI}$ was dissolved in the $\mathrm{AgNO}_{3}$ aqueous solution. The cross-section of a nylon 6-AgI composite was observed by SEM and AgI particles were not observed near the film surface. In addition, the weight gain of the nylon 6-AgI composite decreased for immersion times longer than $1 \mathrm{~h}$ in the $\mathrm{AgNO}_{3}$ solution.

The state of the AgI particles present in the composite films was investigated next. Although the weight of $\mathrm{AgI}$ in nylon 6 was increased, the transparency of the nylon 6-AgI composite was increased with the decrease in the secondary doping immersion temperature; transmittances at $600 \mathrm{~nm}$ for the composites prepared at secondary doping temperatures of $0{ }^{\circ} \mathrm{C}$ and $60{ }^{\circ} \mathrm{C}$ were $73 \%$ and $29 \%$, respectively (primary doping temperature: $20^{\circ} \mathrm{C}$ ). The results imply that the size of $\mathrm{AgI}$ in the composite is smaller when the composite is immersed at a lower secondary doping temperature. Fig. 5 shows SAXS profiles of nylon 6-AgI prepared at different $\mathrm{AgNO}_{3}$ solution immersion temperatures. These profiles were plotted as $I$ vs. $4 \pi \sin \theta / \lambda$, and the inset figure shows Guinier plots $(\log I$ vs. $\left.(4 \pi \sin \theta / \lambda)^{2}\right)$. The Guinier plots exhibit a non-straight line for the scattering profiles, indicating inhomogeneous size distribution of AgI particles in nylon 6-AgI. The smallest radius of inertia of the particles in the composites was estimated from the slope of the straight line drawn between 0.15 and $0.25 \mathrm{~nm}^{-2}$ in $(4 \pi \sin \theta / \lambda)^{2}$, and was ca. $5 \mathrm{~nm}$. Thus, the size of the smallest AgI particle was estimated as ca. $10 \mathrm{~nm}$. The SAXS profiles of the composites prepared at secondary doping temperatures of $40{ }^{\circ} \mathrm{C}$ 
and $60{ }^{\circ} \mathrm{C}$ show an increase in intensity at lower angles, below $0.10 \mathrm{~nm}^{-2}$ in $(4 \pi \sin \theta / \lambda)^{2}$, which implies

that there are larger AgI particles. From these observations, it was considered that the decrease in the transparency of nylon 6-AgI is caused by coarsening of the AgI particles leading to the scattering of visible light.

This method is a simple way to impart conductivity to insulating nylon 6 by doping with AgI. Thus, we investigated the influence of the immersion temperature of the doping solution on the conductivity of the composites. Fig. 6 shows the dependence of the conductivity of the nylon 6-AgI composites on the immersion temperature in (a) $\mathrm{AgNO}_{3}$ and (b) $\mathrm{I}_{2}-\mathrm{KI}$ aqueous solutions. The samples in this figure are the same as those presented in Figs. 2 and 4. For comparison, the conductivity of a bulk $\beta$-AgI tablet prepared by compression molding was also measured. The conductivity of the bulk $\beta$-AgI was $4.1 \times 10^{-7}$ $\Omega^{-1} \mathrm{~cm}^{-1}$, and was approximately in agreement with the previously reported value $\left(3 \times 10^{-7} \Omega^{-1} \mathrm{~cm}^{-1}\right){ }^{10,28}$ The conductivities of the composites increased with the decrease in the immersion temperature, and are in the range from $3.8 \times 10^{-6}$ to $5.8 \times 10^{-5} \Omega^{-1} \mathrm{~cm}^{-1}$. Interestingly, these values are more than one order higher than that of bulk $\beta$-AgI. By comparing Figs. 6(a) and 2, it seems that the conductivity is proportional to the amount of $\mathrm{AgI}$ introduced when only the temperature of the $\mathrm{I}_{2}$-KI solution was changed; the conductivity is doubled as the amount of AgI present in the composite is doubled. On the other hand, comparing Figs. 6(b) and 4, the change of the immersion temperature of the $\mathrm{AgNO}_{3}$ 
solution causes a larger rate of change in conductivity, although the rate of weight change of AgI was smaller than that in the case of immersion temperature dependence of the $\mathrm{I}_{2}-\mathrm{KI}$ solution.

Generally, the effective conductivity for a two-component mixture depends on the mixing mode, and the crudest limits have the following formulae; ${ }^{10,29}$

$$
\begin{gathered}
\sigma_{L}^{-1}=\left(1-v_{2}\right) \sigma_{1}^{-1}+v_{2} \sigma_{2}^{-1} \\
\sigma_{U}=\left(1-v_{2}\right) \sigma_{1}+v_{2} \sigma_{2}
\end{gathered}
$$

where $L$ and $U$ of subscripts are respectively the abbreviations of lower and upper bounds, $v_{2}$ is the volume fraction of the 2 nd component, and $\sigma_{i}$ is the conductivity of the $i$-th component. Equation (2) is frequently applied to interpret the total conductivity of a composite system. ${ }^{30,31}$ The volume fraction of the AgI component contained in the composite was calculated using the density of $\beta$-AgI (5.71 g $\left.\mathrm{cm}^{-3}\right),{ }^{32}$ and it ranged from 13 to $20 \mathrm{vol} \%$. The total conductivities of the nylon 6-AgI composites were calculated using equation (1) or (2) and the conductivities of bulk $\beta$-AgI $\left(4.1 \times 10^{-7} \Omega^{-1} \mathrm{~cm}^{-1}\right)$ and nylon $6\left(1 \times 10^{-15} \Omega^{-1} \mathrm{~cm}^{-1}\right),{ }^{33}$ and the densities of bulk $\beta$-AgI and nylon $6\left(1.14 \mathrm{~g} \mathrm{~cm}^{-3}\right) .{ }^{33}$ Consequently, the conductivities ranged from $1.1 \times 10^{-15}$ to $1.3 \times 10^{-15}$ for equation (1), and from $4.3 \times 10^{-8}$ to $8.5 \times 10^{-8} \Omega^{-1}$ $\mathrm{cm}^{-1}$ for equation (2). The measured conductivity of the composite was at least 2 orders larger than the 
calculated value. This shows that the conductivity of $\beta-\mathrm{AgI}$ in the nylon 6-AgI composite is significantly higher than that of bulk $\beta$-AgI. The value of $\sigma_{U}$ in equation (2) is obtained from a parallel model (i.e. conductive components in the composite system are in contact throughout the sample and form a conductive path). Thus, the conductivity of AgI particles in the composite was measured with an impedance analyzer. As a result, the conductivity was approximately $10^{-1} \Omega^{-1} \mathrm{~cm}^{-1}$. The high conductivity of the AgI particles is near that of $\alpha-\mathrm{AgI}$, rather than that of $\beta$-AgI. This value may be related to the AgI particle size. It has been reported that the ionic conductivity of halides of silver or copper is strongly dependent on the particle size. ${ }^{10,34} \mathrm{~A}$ smaller particle size provides larger ionic conductivity. For example, when the size of $\mathrm{AgBr}$ particles was changed from $1 \mu \mathrm{m}$ to $0.3 \mu \mathrm{m}$, the conductivity was increased from ca. $7 \times 10^{-7} \Omega^{-1} \mathrm{~cm}^{-1}$ to ca. $20 \times 10^{-7} \Omega^{-1} \mathrm{~cm}^{-1} \cdot{ }^{34}$ In the case of AgI, the conductivity at room temperature was increased with the decrease in the particle size, i.e., $1.4 \times 10^{-4} \Omega^{-1}$ $\mathrm{cm}^{-1}$ for $140 \mathrm{~nm}, 6.7 \times 10^{-5} \Omega^{-1} \mathrm{~cm}^{-1}$ for $160 \mathrm{~nm}, 4.0 \times 10^{-5} \Omega^{-1} \mathrm{~cm}^{-1}$ for $440 \mathrm{~nm}$, and $7.0 \times 10^{-6} \Omega^{-1} \mathrm{~cm}^{-1}$ for $680 \mathrm{~nm}^{10}$ As shown in Fig. 5, the size of the AgI particles is larger than at least $20 \mathrm{~nm}$; therefore, there is a possibility that the small size of the AgI particles is related to the high ionic conductivity.

The structure of the AgI crystal is another significant factor to be considered. The ion transport mechanism of $\mathrm{AgI}$ is attributed to lattice defects, so it is anticipated that a more disordered crystal lattice imparts higher ionic conductivity. As shown in Fig. 1, the crystallinity of AgI is considerably 
low, in other words, the AgI of the composite contains many lattice defects. By annealing the nylon 6-AgI at $160^{\circ} \mathrm{C}$, the diffraction peaks of $\beta$-AgI became sharper and the crystallinity increased, and the conductivity was reduced by one order of magnitude. It is therefore considered that the high defect density is likely one factor of high ionic conductivity of $\mathrm{AgI}$ in the composite. Besides, a highly conductive structure of $\mathrm{AgI}$ at room temperature has been reported. ${ }^{37,38} \mathrm{AgI}$ usually possesses substructures of a sequence of hexagonal close packed $\beta$ - $\mathrm{AgI}(2 \mathrm{H})$ and of a sequence of cubic close packed $\gamma$-AgI (3C). Davis et al. reported a polytype structure of $21 \mathrm{H}^{35}$ and $7 \mathrm{H},{ }^{36}$ and Lee at al. reported a $7 \mathrm{H}$ structure. ${ }^{37}$ They described that the $7 \mathrm{H}$ polytype structure of $\mathrm{AgI}$ is responsible for the significant enhancement of conductivity in a composite of $\mathrm{AgI}$ embedded in a $\mathrm{Al}_{2} \mathrm{O}_{3}$ matrix (ca. $10^{-3} \Omega^{-1} \mathrm{~cm}^{-1}$, AgI: $\left.\mathrm{Al}_{2} \mathrm{O}_{3}(40 \mathrm{~m} / \mathrm{o})\right) .{ }^{37}$ The $7 \mathrm{H}$ structure can be approximately considered as a heterostructure alternation of $\beta$-AgI and $\gamma$-AgI (i.e. $\beta / \gamma / \beta / \gamma / \beta / \gamma \ldots$..). If space charge effects at a given $\beta / \gamma$ interface in such a heterostructure can be assumed, most silver ions would then be disordered and effective as charge carriers, explaining the significant conductivity enhancement in the composite. ${ }^{38}$ These polytype structures exhibit some diffraction peaks, but it is difficult to recognize them in our composite because they are obscured by other diffraction peaks ( $\beta$-AgI or nylon 6), or are of very weak intensity. However, the possibility of an AgI polytype structure in our composite can not be excluded. At any rate, it is considered that the high conductivity is related to both particle size and the crystallite structure. 


\section{Formation of anisotropic AgI in oriented nylon 6 film}

We investigated the influence of the orientation of the nylon 6 matrix on the formation of AgI. AgI particles in the drawn composite film were observed by SEM. Figs. 7(a) and (b) show the cross-sectional SEM images of the drawn composite film; cross-sections (a) parallel, and (b) perpendicular to the direction of drawing. In the figures, the white grains are AgI particles which are densely distributed in the composite, except at the film surface. Larger anisotropic AgI grains are in the central part of the film and smaller anisotropic AgI gains are situated around the larger AgI grains. The size of the AgI particles gradually decreases closer proximity to the film surface. The inhomogeneous size distribution of AgI particles may be related to the distribution of polyiodide ions, because the migration speed of polyiodide ions into nylon 6 is abnormally fast, ${ }^{39}$ and a large amount of iodine component is entered due to the strong interaction between nylon 6 and iodine.

Fig. 8 shows the XRD photographs of (a) a random nylon 6 film, (b) a random nylon 6-AgI composite film, (c) a drawn nylon 6 film, and (d) a drawn nylon 6-AgI composite film. The incident X-ray beam was focused from the direction normal to the film surface. In Fig. 8(b), the diffraction assigned to $\beta-\mathrm{AgI}$ is shown as Debye-Scherrer rings, indicating that the crystallite orientation of $\mathrm{AgI}$ is random in the film plane. On the other hand, for the drawn composite film shown in Fig. 8(d), the 
diffractions from $\beta$-AgI exhibit a preferred crystallite orientation. This crystallite orientation of $\mathrm{AgI}$ is dependent on the orientation of the nylon 6 molecule. Precursor polyiodide ions are sorbed with orientation influenced by the orientation of the nylon 6 molecular chains. ${ }^{40,41}$ Fig. 9 shows the polarized Raman spectra of the drawn nylon 6 film after primary iodine doping. The angles between the polarized plane of the laser and the drawn direction of the nylon 6 are $0^{\circ}$ (parallel), $30^{\circ}, 60^{\circ}$ and $90^{\circ}$ (perpendicular). A strong band assigned to $\mathrm{I}_{5}{ }^{-}\left(170 \mathrm{~cm}^{-1}\right)$ was observed at $0^{\circ}$, while the band at 230 $\mathrm{cm}^{-1}$ (assigned to $\mathrm{I}_{3}^{-}$) was mainly observed with perpendicular polarization. This means that polyiodide ions are oriented as shown in the illustration of Fig. 9, and this agrees well with the reports by Murthy et $a{ }^{4},{ }^{42,43}$ and Lee et al. ${ }^{44}$ Linear $\mathrm{I}_{5}^{-}$ion chains exist in the complex with the long axes parallel to the chain axis. Linear $\mathrm{I}_{3}{ }^{-}$ion chains exist with the long axes perpendicular to the chain axis. We consider that the orientation of polyiodide ions causes the crystallite orientation and anisotropic particles of AgI. This consideration is supported by the following result. We attempted to introduce $\mathrm{AgI}$ into a silk fibroin fiber, which is a natural polyamide and has high crystallite orientation. However, the silk fibroin fiber could only sorb polyiodide ions in the amorphous part with low molecular orientation, and AgI particles with random orientation were formed by reaction with $\mathrm{Ag}^{+}$ions during secondary doping. ${ }^{45}$ Therefore, it is considered that the orientation of AgI in the drawn composite is influenced by orientation of the polyiodide ions. 
Since the anisotropy of AgI in a nylon 6 matrix may provide anisotropically conductive properties, the electrical conductivity of the drawn composite was measured. Fig. 10 shows the temperature dependence of the electrical conductivity of a drawn nylon 6-AgI composite film prepared at primary and secondary doping immersion temperatures of $15{ }^{\circ} \mathrm{C}$. Open and filled circles show conductivities parallel $\left(\sigma_{\|}\right)$and perpendicular $\left(\sigma_{\perp}\right)$ to the drawn (chain) axis, respectively. The electrical conductivity $\sigma_{\|}$is one order higher than $\sigma_{\perp}$ (There is no measurement direction dependence of conductivity for random nylon 6-AgI composite.). The slopes of the conductivity curves change above $100{ }^{\circ} \mathrm{C}$ (ca. $\left.2.7 \times 10^{-3} \mathrm{~K}^{-1}\right)$. This temperature is probably the transition temperature from $\beta$-AgI to $\alpha$-AgI, because the conductivity is increased due to the transition to highly conductive $\alpha$-AgI. This was confirmed by differential scanning calorimetry (DSC) of the drawn composite film, which showed an endothermic peak indicating the crystal transition at ca. $100^{\circ} \mathrm{C}$. In general, the transition temperature from $\beta$-AgI to $\alpha$ - $\mathrm{AgI}$ is at $147^{\circ} \mathrm{C}$, while the transition temperature of the drawn nylon 6-AgI composite was shifted to $40{ }^{\circ} \mathrm{C}$ lower. The lowering of the transition temperature is related to an excess of $\mathrm{Ag}^{+}$ions against the stoichiometric composition of AgI, but the detailed reasons for this observation are yet to be clarified and are now under investigation. From the above results, the nylon 6-AgI composite with anisotropic electrical conductivity was prepared via a complex of oriented polyiodide ions in nylon 6 . 


\section{Mechanism of AgI formation}

The reaction path for polyiodide ions, such as $\mathrm{I}_{3}{ }^{-}$and $\mathrm{I}_{5}{ }^{-}$, with $\mathrm{AgNO}_{3}$ in nylon 6 is next considered.

For $\mathrm{I}_{3}{ }^{-}$as an example, two possible pathways can be derived as follows:

$$
\begin{gathered}
\mathrm{I}_{3}{ }^{-}+\mathrm{AgNO}_{3} \rightarrow \mathrm{AgI}+\mathrm{NO}_{3}{ }^{-}+\mathrm{I}_{2} \\
\mathrm{I}_{3}{ }^{-}+3 \mathrm{AgNO}_{3}+2 \mathrm{e}^{-} \rightarrow 3 \mathrm{AgI}+3 \mathrm{NO}_{3}{ }^{-}
\end{gathered}
$$

For reaction (I), the molar ratio of $\mathrm{I}_{3}^{-}$(reactant) to AgI (product) in the equation is 3:1, while for reaction (II), the molar ratio is $1: 1$. In the case of $\mathrm{I}_{5}{ }^{-}$, the molar ratios are 5:1 and $1: 1$ when the reactions proceed in the same manner as reactions (I) and (II), respectively. In order to clarify the reaction, the relationship between the amounts of iodine in the nylon 6-polyiodide complex and $\mathrm{AgI}$ in nylon 6-AgI was investigated by the determination of weight gains after primary and secondary doping. Primary and secondary doping were both carried out at $15{ }^{\circ} \mathrm{C}$. As a result, the weight gain by iodine in primary doping was $0.581 \mathrm{~g}$ to $1 \mathrm{~g}$ of original nylon $6\left(4.578 \mathrm{mmol} \mathrm{g}^{-1}\right),{ }^{46}$ while the amount of AgI was $1.050 \mathrm{~g}$ (4.472 $\mathrm{mmol} \mathrm{g}^{-1}$ ) per $1 \mathrm{~g}$ of original nylon 6. That is, the molar ratio of I and AgI was approximately 1:1. This result supports the approval of reaction (II). This is supported by the fact that chromatic $\mathrm{I}_{2}$ was not observed during the secondary doping reaction. The number of moles of AgI is somewhat 
lower than that of iodine. This is attributed to the elution of a small amount of $\mathrm{AgI}$ into the $\mathrm{AgNO}_{3}$

solution during secondary doping. A supply source of electrons for reaction (II) to proceed is necessary, but it has not yet been clarified. Both $\mathrm{I}_{3}{ }^{-}$and $\mathrm{NO}_{3}{ }^{-}$ions are strong oxidizing agents and have low possibility to donate electrons; therefore, it is being considered that the electrons are supplied from the matrix polymer.

\section{Antibacterial property}

As supplementary data, the antibacterial property of the composite was exhibited. Table 1 represents the resulting data of antibacterial property against three kinds of bacteria, Staphylococcus aureus, Klebsiella pneumoniae and Pseudomonad aeruginosa. Neat nylon 6 as a control has no antibacterial property, because the colony forming units for all bacteria are considerably increased after incubation.

On the other hand, for nylon 6-AgI, the colony forming units are almost zero, although the amount of included AgI in the composite was considerably limited (only several wt. percent), which indicates that the composite has a high bacteria killing property. AgI is a very insoluble compound in water and the particles are in the inner part of the nylon 6 matrix, thus the antibacterial property can be expected to be persistent for long time use. 


\section{CONCLUSIONS}

A nylon 6 film complexed with polyiodide ions was immersed in an aqueous solution of $\mathrm{AgNO}_{3}$, and a composite, including a large amount of $\beta$-AgI particles, was successfully obtained. The amount of AgI formed in the matrix was strongly dependent on the temperatures of the immersion solutions. The composite exhibited conductivity in the order of $10^{-5} \Omega^{-1} \mathrm{~cm}^{-1}$. In addition, the transparency of the composite prepared at lower immersion temperature was relatively high, although the weight of the AgI content exceeded that of the matrix polymer. In the oriented nylon 6 film, AgI was formed as anisotropic particles, and displayed crystallite orientation, which introduced anisotropic conductivity to the composite. This is attributed to the orientation of polyiodide ions, as the precursor of AgI, in the orientated nylon 6 chain. Other interesting properties, strong antibacterial activity and good UV absorption (the data of UV-VIS was not shown) were possessed, so it can be said that the nylon 6-AgI composite is an attractive material.

\section{References}

1. Otterwill, R. H.; Woodbridge, R. F. J Colloid Sci 1961, 16, 581.

2. Berry, C. R. Phys Rev 1967, 161, 848.

3. Saijo, H.; Iwasaki, M.; Tanaka, T.; Matsubara, T. Photogr Sci Eng 1982, 26, 92. 
4. Smith, P. V. J Phys Chem Solids 1976, 37, 589.

5. Tubandt, C.; Lorenz, E. Z. Z Physik Chem 1914, 87, 513.

6. Tatsumisago, M.; Shinkuma, Y.; Minami, T. Nature 1991, 354, 217.

7. Owens B. B.; Argue G. R. Science 1967, 157, 308.

8. Owens B. B.; Argue G. R. J Electrochem Soc 1970, 11, 898.

9. Guo, Y. -G.; Lee, J. -S.; Maier, J. Adv Mater 2005, 17, 2815.

10. Ida T.; Kimura, K. Solid State Ionics 1998, 107, 313.

11. Validžić, I. Lj.; Jokanović, V.; Uskoković, D. P.; Nedeljković, J. M. J Euro Ceram Soc 2007, 27, 927.

12. He, H.; Wang Y.; Chen, H.; Solid State Ionics 2004, 175, 651.

13. Uvarov, N. F.; Hairetdinov, E. F.; Bokhonov, B. B.; Bratel, N. B. Solid State Ionics 1996, 86-88, 573.

14. Chen, S. H.; Ida, T.; Klimura, K. J Phys Chem B 1998, 102, 6169.

15. Rotstein H.; Tannenbaun, R. In Synthesis, Functionalization and Surface Treatment of nanoparticles; Baraton, M. I., Eds.; American Scientific Publishers: California, 2003; pp $103-126$.

16. Caseri, W. Macromol Rapid Commun 2000, 21, 705. 
17. Bradley, J. S. In Clusters and Colloids; Schmid, G., Eds.; VCH: Weinheim, 1994; p 523.

18. Mayer, A. B. R. Polym Adv Technol 2001, 12, 96.

19. Gubin, S. P. Colloids Surf A 2002, 202, 155.

20. Gotoh, Y.; Kanno, T.; Fujimori, Y.; Ohkoshi, Y.; Nagura, M.; Akamatsu, K.; Deki, S. Polym J 2003, 35, 960 .

21. Fujimori, Y.; Gotoh, Y.; Kohda. Y.; Nagura, M.; Ohkoshi, Y. Sen'i Gakkaishi 2004, 60, 237. (in Japanese).

22. Fujimori, Y.; Gotoh, Y.; Tamaki, N.; Ohkoshi, Y.; Nagura, M. J Mater Chem 2005, 15, 4816.

23. Wang, Y.; Ye, C.; Wang G.; Zhang, L.; Applied Physics Litters 2003, 82, 4253.

24. Gotoh, Y.; Kanno, T.; Ohkoshi, Y.; Nagura, M.; Akamatsu, K.; Mizuhata, M.; Deki, S. Proceedings of International Synposium on Small Particles and Inorganic Cluster, 11, 11, B-XII-8, Strasbourg, 2002.

25. Joint Committee on Powder Diffraction Standards (JCPDS), files File No.9-374.

26. Abu-isa, I. A. J Applied Polym Sci 1971, 15, 2865.

27. Yoshida, K.; Endo, M. Kogyo Kagaku Zasshi 1956, 59, 1074. (in Japanese).

28. Shahi, K.; Wagner, Jr., J. B. J Electrochem Soc 1981, 128, 6.

29. Beran, M. J. P. In Statistical Continuum Theories; Wiley Inter, science: New York, 1968, pp. 
$181-256$.

30. Shapiro, I.; Kolthoff, I. M. J Chem Phys 1947, 15, 41.

31. Jow, T.; Wagner, Jr, J. B. J Electrochem Soc 1979, 126, 1963.

32. In CRC Handbook of Chemistry and Physics; Lide, D. R., Eds.; CRC: Boca Raton, 76th Edn., 1995; pp 4-48.

33. In Polymer Handbook; Brandrup, J.; Immergut, E. H., Eds.; Wiley: Toronto, 3rd Edn., 1989; p V-114

34. Takada, S. Jpn J Appl Phys 1973, 12, 190.

35. Davis, B. L.; Petersen, R. L. Crystal Lattice Defects 1970, 1, 275.

36. Davis, B. L.; Petersen, R. L. Crystal Lattice Defects 1974, 5, 235.

37. Lee, J.-S.; Adams, S.; Maier, J. Solid State Ionics 2000, 136-137, 1261.

38. Lee, J.-S.; Adams, S.; Maier, J.; J Electrochem Soc 2000, 147, 2407.

39. Kawaguchi, A. Tsurutani, N. Miyaji, H. Spring-8 User Exp Rep 2000, 5, 354.

40. Murthy, N. S. Macromolecules 1987, 20, 309.

41. Kawaguchi, A. Polymer 1992, 33, 3981.

42. Murthy, N. S.; Szollosi, A. B.; Sibilia, J. P.; Krimm, S. J Polym Sci Polym Phys Ed 1985, 23, 2369. 
43. Burzynski, R.; Prasad, P. N.; Murthy, N. S. J Polym Sci Polym Phys Ed 1986, 24, 133.

44. Lee, Y. H.; Porter, R. S. J Macromol Sci Phys B 1995, 34, 295.

45. Unpublished data.

46. The weight gains by iodine in the primary doping were determined as follows; the weight gain $0.606 \mathrm{~g}$ per $1 \mathrm{~g}$ of original nylon 6 was measured after primary doping. This sample contained potassium ions as a counter ion. Therefore, TGA measurement was conducted to in an air flow. Only KI remained as an ash after heating at $550{ }^{\circ} \mathrm{C}$, and the amount of $\mathrm{KI}$ introduced into the iodinated nylon 6 was determined as $0.111 \mathrm{~g}$ per $1 \mathrm{~g}$ of original nylon 6 , thus the amount of $\mathrm{K}^{+}$ ions was $0.025 \mathrm{~g}$ per $1 \mathrm{~g}$ of original nylon 6 . Consequently, the amount of iodide was $0.581 \mathrm{~g}$ against $1 \mathrm{~g}$ of original nylon 6 .

\section{Acknowledgments}

The research was supported by the Sasakawa Scientific Research Grant from The Japan Science Society and by a Grantin-Aid for 21st Center of Excellence (COE) Research from the Japanese Ministry of Education, Culture, Sports, Science, and Technology. The SAXS experiments were performed in the Photon Factory of High Energy Accelerator Research Organization with the approval number 2006G067. The authors thank Mr. Takashi 
Kanno and Mr. Akihisa Fuluta for his experimental assistance. 


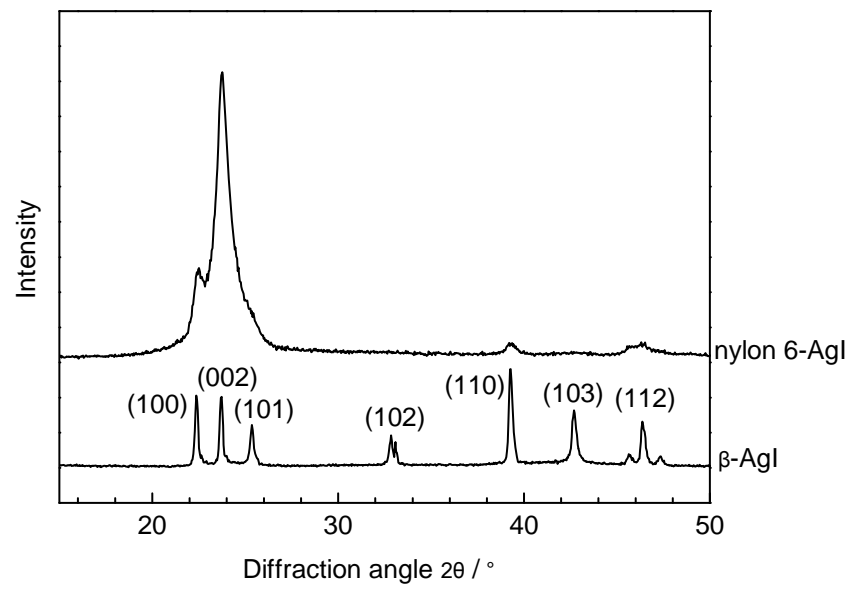

Fig. 1. X-ray diffraction pattern of nylon 6-AgI and $\beta$-AgI powder.

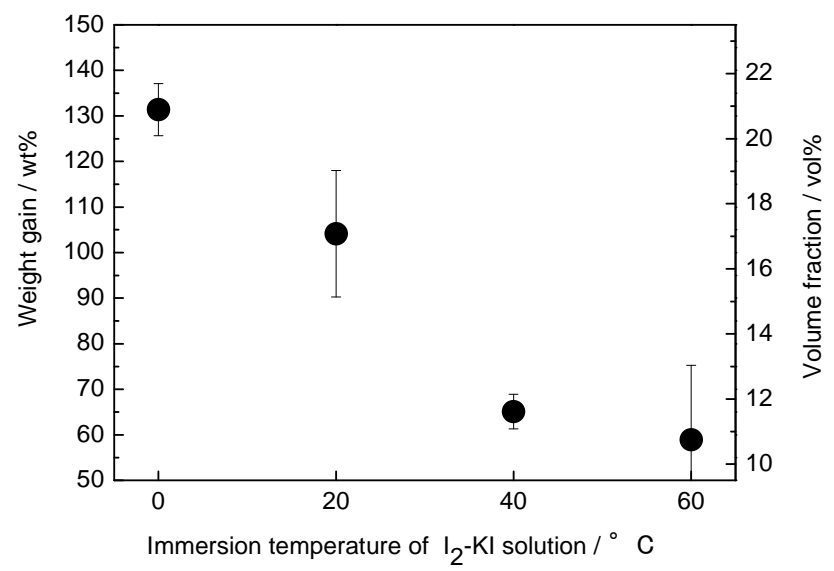

Fig.2 Dependence of the weight gain of nylon 6-AgI, or the volume fraction of AgI in nylon 6-AgI, on the immersion temperature of the $\mathrm{I}_{2}-\mathrm{KI}$ aqueous solution $\left(\mathrm{AgNO}_{3}\right.$ aqueous solution fixed at $\left.20^{\circ} \mathrm{C}\right)$. 


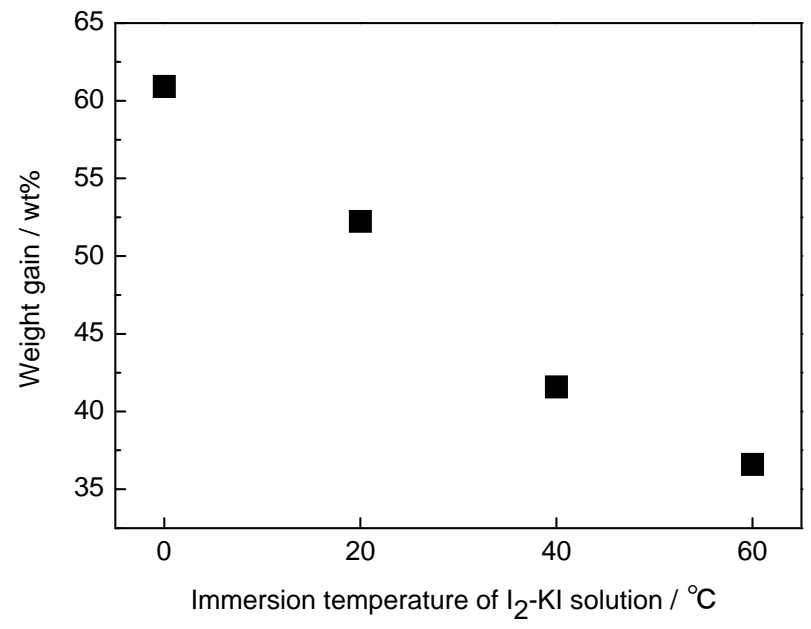

Fig.3 Dependence of weight gain of nylon 6 doped with iodide ion on the immersion temperature of the $\mathrm{I}_{2}-\mathrm{KI}$ aqueous solution.

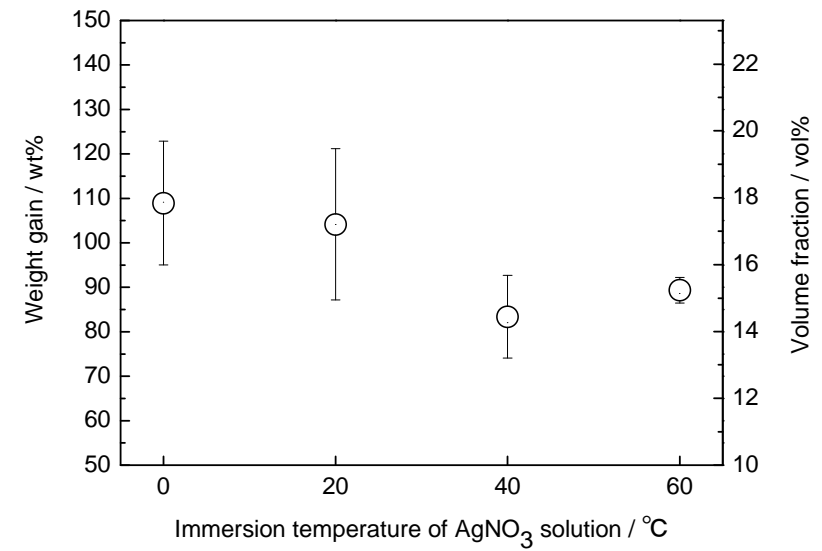

Fig.4 Dependence of the weight gain in nylon 6-AgI, or volume fraction of AgI in nylon 6-AgI, on the immersion temperature of $\mathrm{AgNO}_{3}$ aqueous solution $\left(\mathrm{I}_{2}-\mathrm{KI}\right.$ aqueous solution fixed at $\left.20^{\circ} \mathrm{C}\right)$. 


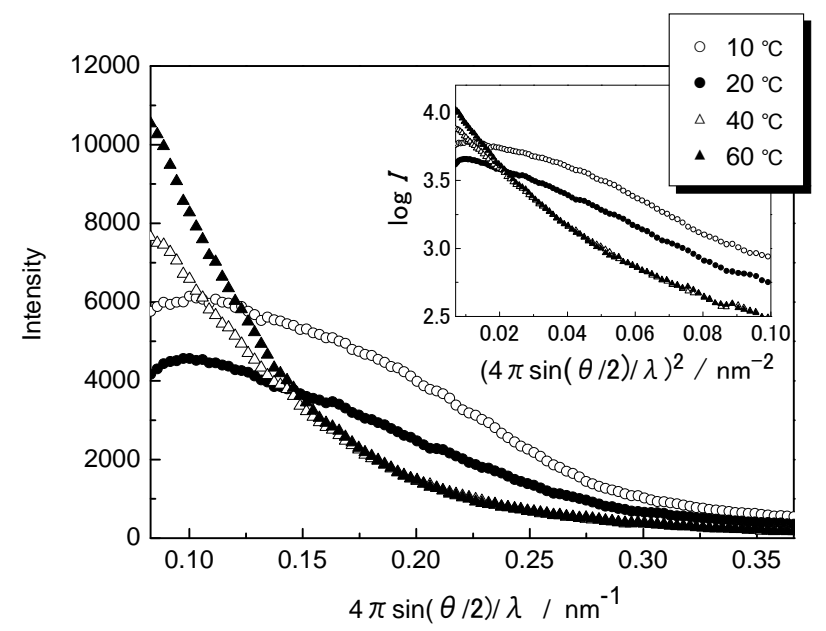

Fig.5 SAXS profiles of nylon 6-AgI films prepared from $\mathrm{AgNO}_{3}$ aqueous solution at different temperatures ( $\mathrm{I}_{2}-\mathrm{KI}$ aqueous solution temperature was fixed at $\left.20^{\circ} \mathrm{C}\right)$.
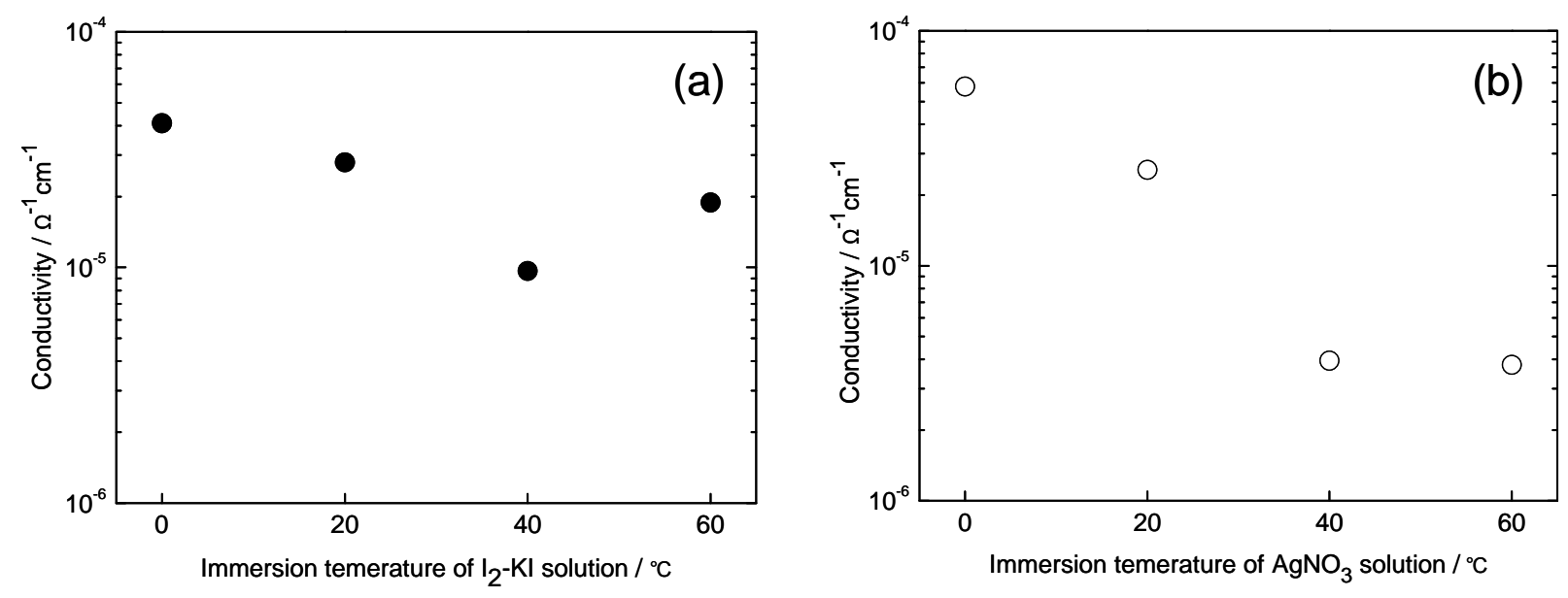

Fig.6 Dependence of the conductivity of nylon 6- $\mathrm{AgI}$ on the immersion temperature of (a) $\mathrm{AgNO}_{3}$ and

(b) $\mathrm{I}_{2}-\mathrm{KI}$ aqueous solutions. 

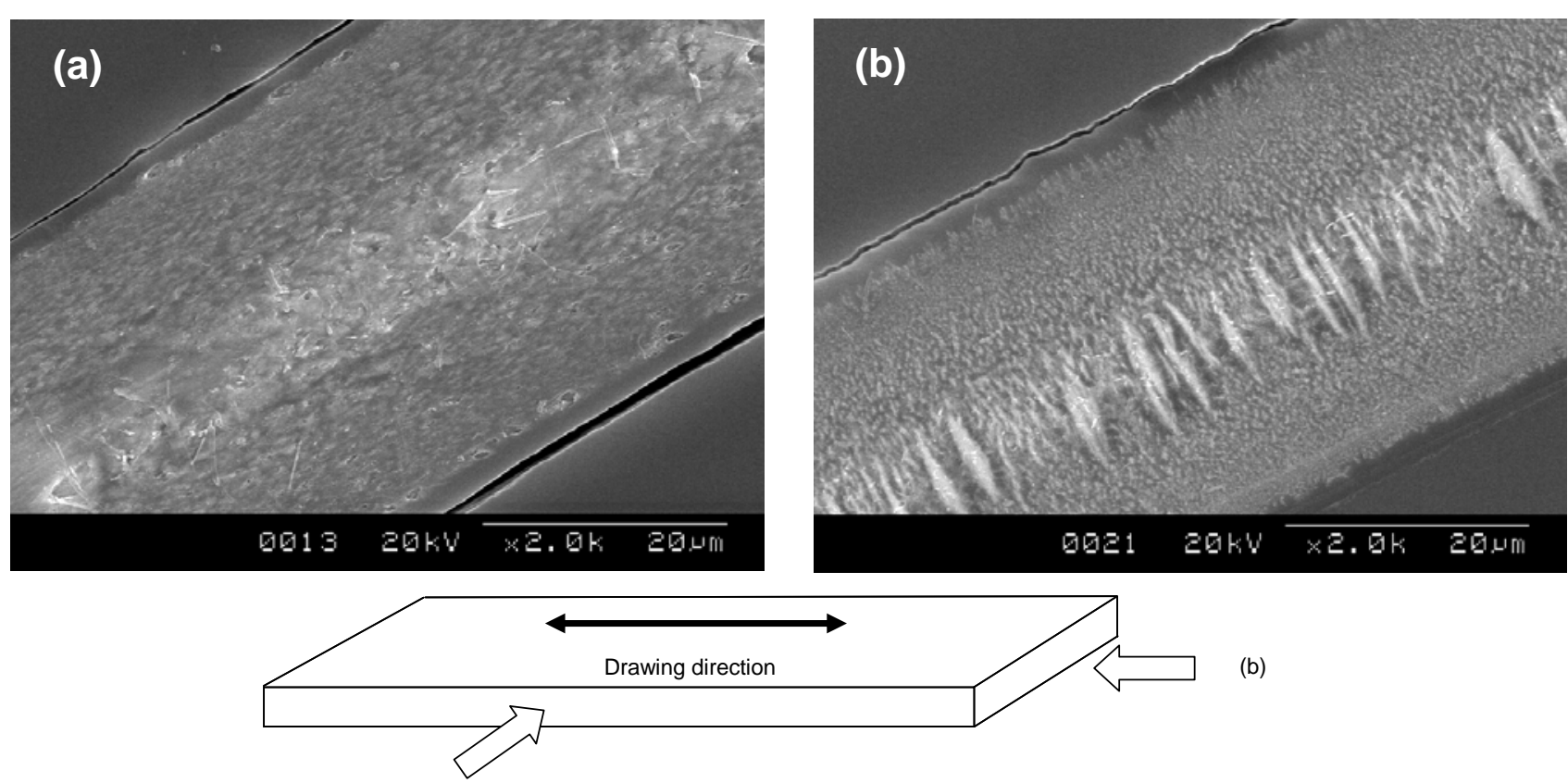

(b)

(a)

Fig.7 Cross-sectional SEM images of drawn nylon 6-AgI: (a) parallel and (b) perpendicular to the direction of drawing. 

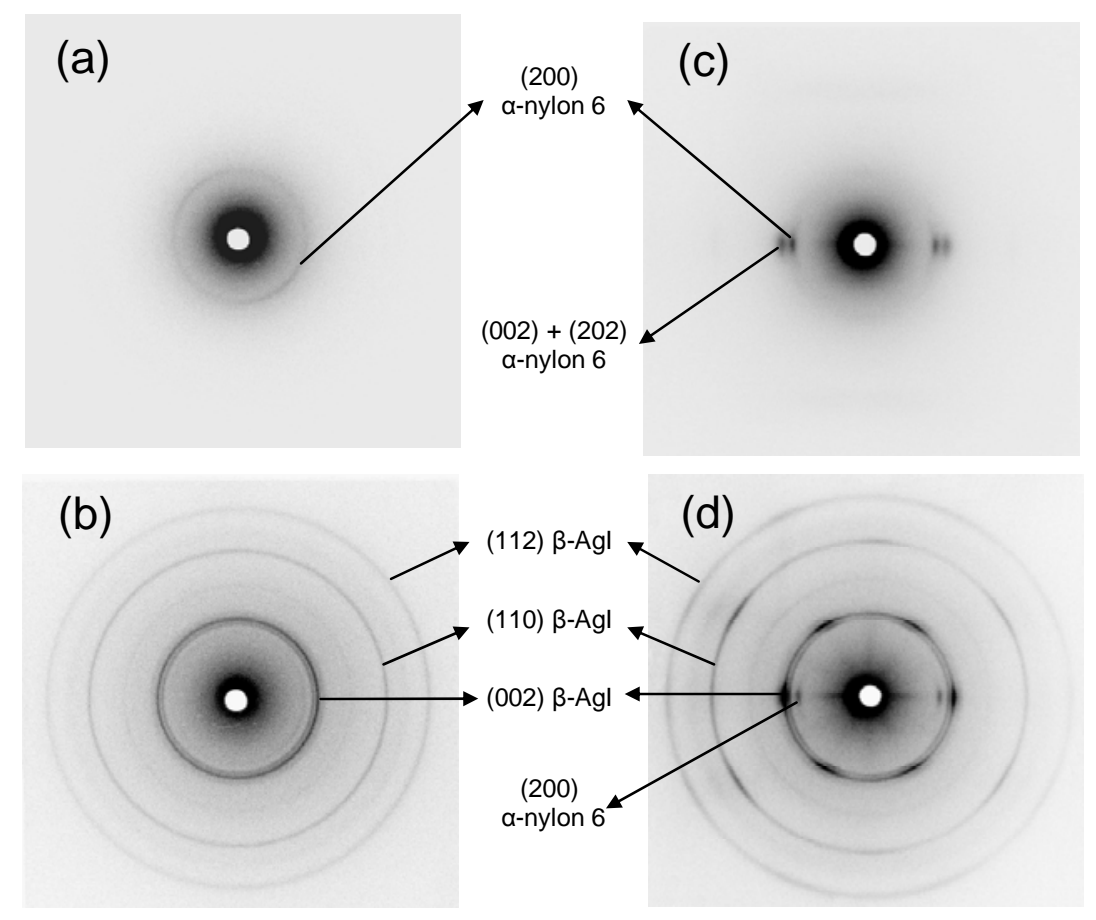

Fig.8 X-ray diffraction photographs of (a) a random nylon 6 film, (b) a random nylon 6-AgI film, (c) a drawn nylon 6 film, and (d) a uniaxially orientated nylon 6-AgI film. The incident X-ray beam was directed perpendicular to the film surface.

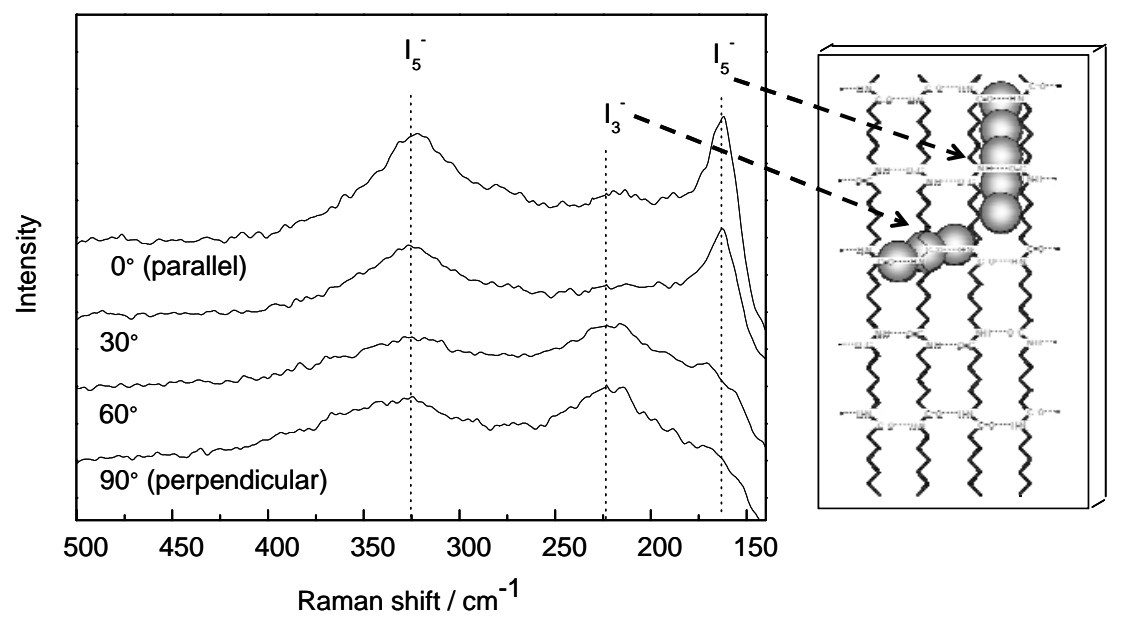

Fig. 9. Polarized Raman spectra of drawn nylon 6 films after primary iodine doping. Different angles show the direction between the polarized plane of the laser and the drawing direction of the nylon 6 . 

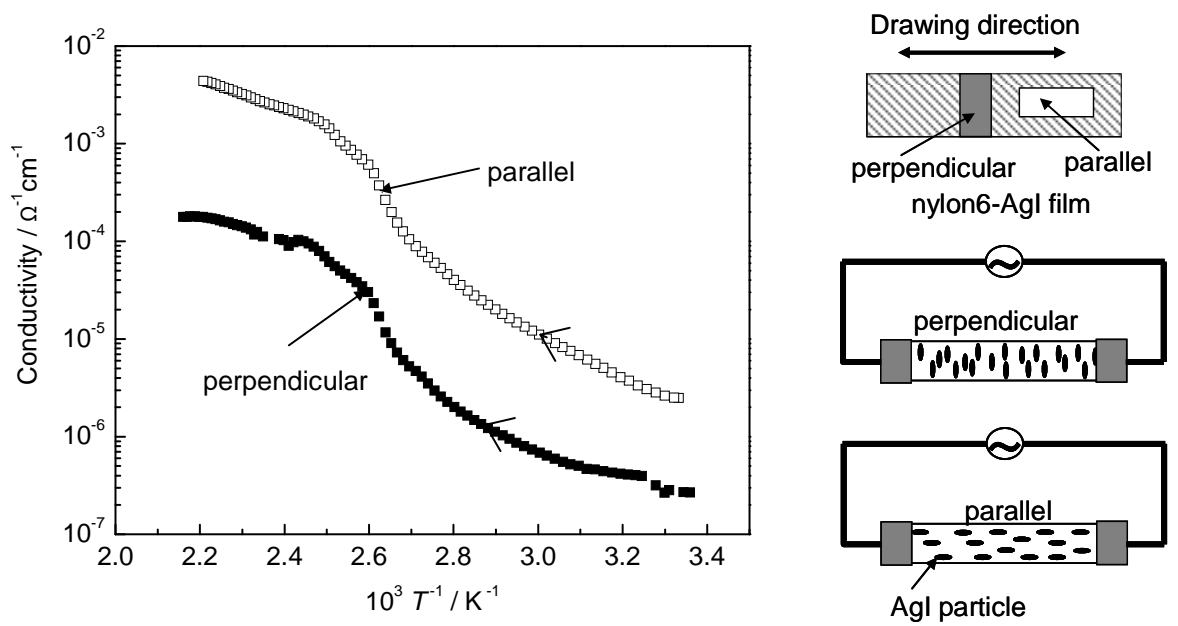

Fig.10 Temperature dependence of the electrical conductivity of nylon 6-AgI composite: parallel ( $\square$ )

and perpendicular $(\boldsymbol{\square})$ to the drawing direction.

Table 1 Antibacterial property of nylon 6 and nylon 6-AgI composite.

\begin{tabular}{lcccc}
\hline \multirow{2}{*}{ Kinds of bacteria } & \multicolumn{4}{c}{ Colony forming unit (CFU / ml) } \\
\cline { 2 - 5 } & \multicolumn{2}{c}{ nylon 6 (control) } & \multicolumn{2}{c}{ nylon 6-AgI } \\
\cline { 2 - 5 } & Initial & After $18 \mathrm{~h}$ & $\mathbf{I n i t i a l}$ & After $18 \mathrm{~h}$ \\
\hline Staphylococcus aureus & $\mathbf{8 . 8 5 \times 1 0 ^ { 3 }}$ & $2.44 \times 10^{6}$ & $\mathbf{8 . 8 5} \times 10^{3}$ & $10>$ \\
Klebsiella pneumoniae & $3.87 \times 10^{4}$ & $4.30 \times 10^{7}$ & $3.87 \times 10^{4}$ & $10>$ \\
Pseudomonas aeruginosa & $4.24 \times 10^{4}$ & $2.51 \times 10^{8}$ & $4.24 \times 10^{4}$ & $10>$ \\
\hline
\end{tabular}

